\title{
Ambient Levels of Primary and Secondary Pollutants in a Residential Area: Population Risk and Hazard Index Calculation over a Three Years Study Period
}

\author{
${ }^{1}$ S. Al-Salem and ${ }^{2}$ A. Al-Fadhlee \\ ${ }^{1}$ Petrochemical Processes Program Element, Petroleum Research and Studies Center \\ Kuwait Institute for Scientific Research, P.O. Box 24885, Safat 13109, The State of Kuwait \\ ${ }^{2}$ Planning Department, International Marketing Sector, Kuwait Petroleum Corporation, P.O. Box 26565, \\ 13126, Safat, The State of Kuwait
}

\begin{abstract}
This paper aims at presenting data collected over the period of three years (2004-2006) in a residential area in the state of Kuwait. The data collected include ambient levels of primary and secondary pollutants with a number of metrological parameters. A series of unfiltered and filtered concentration roses were plotted to determine the predominant sources as well as the prevailing winds affecting the area under investigation. Local and international air quality regulations were cross referenced over the course of this study. The main objective was to determine whether this residential area could be considered as a safe site for further urban estate development and the risk of the population residing exposed to carcinogens in the ambient air. Although the hazard index values were within the safe range, the population affected with cancer due to benzene inhalation was increasing based on cancer risk assessment calculations.
\end{abstract}

Key words: Concentration Rose, Hazard Index, Carcinogens

\section{INTRODUCTION}

The increasing numbers of cancer patients and treatment requests are increasing in the state of Kuwait annually is posing a serious threat to society in general ${ }^{[1]}$. Industrial sites in the wholesome of the region are considered as a primary source of airborne pollutants ${ }^{[2-}$

${ }^{3]}$. Many primary and secondary pollutants were noticed to be increasing over the past two decades. Military activities in the Arabian Gulf region as a war zone is also considered as a major source of air pollution in terms of process cause and effect. Human related activities are too a major source that adds up to the total ambient load of air pollutants. Restaurants and parking complexes are both emitters of gases such as methane $\left(\mathrm{n}-\mathrm{CH}_{4}\right), \mathrm{NOx}$ and Carbon Monoxide (CO) due to the nature of their work.

Of the 188 hazardous air pollutants (HAPs) listed in the Clean Air Act, only a handful have information on human health effects, derived primarily from animal based and occupational studies. Lack of consistent monitoring data on ambient air toxics makes it even more difficult to assess the extent of low-level, chronic, ambient exposures to HAPs that could affect human health, and limits attempts to prioritize and evaluate policy initiatives for emissions reduction ${ }^{[4]}$. In many previous studies scientists used pollutant levels in water and/or air samples to determine cancer and population risk; establishing a better understanding of the nature of these contaminants. Smith ${ }^{[5]}$ presented a comparison of probabilistic and deterministic health risk estimates based on data from an industrial site in the northeastern United States. The risk assessment considered exposures to volatile solvents by drinking water ingestion and showering. The probabilities accounted for gave a $95 \%$ match in that study. A number of passive samples were analyzed in Al-Salem and Bouhamrah study ${ }^{[6]}$. A number of airborne carcinogens were monitored in an industrial site in Kuwait. These carcinogens include benzene, di bromo chloro methane, bromoform and chloroform. A cancer risk assessment and populations risk calculations were carried out based on these ambient levels. The benzene load gave 6 cases per a million affected with cancer based on ambient levels and assuming that benzene was the only available carcinogen in the air.

In this study, data collected from a residential area in the state of Kuwait (Fahaheel residential area) include primary and secondary pollutants ambient levels. Pollutants include: $\mathrm{CH}_{4}, \mathrm{SO}_{2}$, Total Reduced Sulfur (TRS), NO, NO2, NOx, $\mathrm{C}_{6} \mathrm{H}_{6}, \mathrm{NH}_{3}, \mathrm{CO}$ and Total non-methane hydrocarbons $(\mathrm{HCnM})$. The data
Corresponding Author:
Eng. Al-Salem, Sultan M.S., Petrochemical Processes Program Element, Petroleum Research and Studies Center, Kuwait Institute for Scientific Research, P.O.Box 24885, Safat 13109, The State of Kuwait, Tel: +965-9677200 
collected also include major metrological parameters, i.e. \%relative humidity, wind speed and direction as well as ambient temperature. The collection period was three years starting from January 2004 till December 2006. The main objective was to establish whether the area is considered as a safe site for residences in terms of Hazard Index (HI) calculations as well as determining the annual population risk resulting from benzene exposure as a main carcinogen agent in the ambient air. The authors don't have any prior knowledge of any attempts in this area of research especially based on ambient not personal exposure levels.

\section{MATERIALS AND METHODS}

Ambient sampling and software: The data collected in this study include primary pollutants levels in the ambient; collected from the central location main health center of Fahaheel from 15 meters height from sea level. The ambient air samples were drawn from a fixed probe (Group Tek. Model, 3-5 m, The State of Kuwait; Fixed Photolytic converter, Group Tek. Model, The State of Kuwait, Al-Husaini Agency) located on top of the building and were analyzed by different primary pollutants analyzers (Whatman 41, Air sample Grasbey-Anderson Ltd., 1\% tolerance) all connected with central online data acquisition system managed and controlled by EnviDAS software. The program transformed the data into Microsoft Office 2003, EXCEL program spreadsheets and stored for consecutive three months raw data. The data were on two different spans; original five minute intervals and hourly average. The pollutants collected included methane $\left(\mathrm{CH}_{4}\right)$, Benzene $\left(\mathrm{C}_{6} \mathrm{H}_{6}\right), \mathrm{NOx}, \mathrm{NO}_{2}, \mathrm{H}_{2} \mathrm{~S}, \mathrm{NO}$, $\mathrm{O}_{3}$, Total Reduced Sulfur (TRS) and total solid particulates, $\mathrm{PM}_{10}$. The data collected also included metrological parameters, which were; \% relative humidity, ambient temperature, wind speed $(\mathrm{m} / \mathrm{s})$ and direction in degrees. The main health center was chosen as a receptor point for being adjacent to the MAA refinery as well as the main highway. This is the central location in Fahaheel area which has all major pollution sources of airborne pollutants around in $5 \mathrm{~km}$ circle. On the south side there are residential houses are very close to the refineries and petrochemical industries. In order to execute the source determining step, all potential sources must be referred to the receptor location and respective window of wind direction, influencing the measurements.
Table 1: Sources with respect to corridor of wind direction.

\begin{tabular}{ll}
\hline Position in degrees & Source \\
\hline $0-135$ & Down town area \\
$135-255$ & Refineries, petroleum and petrochemical industries \\
$255-300$ & Oil production facilities (Burgan) \\
$300-360$ & $\begin{array}{l}\text { Traffic line sources (Highway), gas stations and sports } \\
\text { clubs }\end{array}$ \\
\hline
\end{tabular}

Filtration procedure for the data points were preformed by discarding zero \& span check points, source hiccup values. Equation 1 show the $\mathrm{OX}{ }^{[2-3]}$ relation used to filter the raw data points for $\mathrm{NO}$ and ozone titration. Any value contradicting $\mathrm{NO}$ and $\mathrm{O}_{3}$ or $\mathrm{NO}_{\mathrm{x}}$ and $\mathrm{OX}$ were discarded.

$\mathrm{OX}\{[=]=\mathrm{ppb}\}=\mathrm{O}_{3}+\mathrm{NOx}-\mathrm{NO}$ (1)

Where:

$\mathrm{OX}=$ the concentration of oxides in the ambient in ppb; Methane concentrations points below $1.3 \mathrm{ppm}$ were discarded due to malfunctioning of the instruments from particulate accumulation, photo oxidation rxn's, choking or $\mathrm{OH}^{-}$ion presence. The average measured values near the sources were considered chemical fingerprints of the sources under investigation. The chemical fingerprints were avarage readings of concetrations recorded on the sources location. The source determining step was performed by drawing the concentration and wind direction for the filtered data and using double axis plotting to relate wind speed and wind direction with the mean values of methane concentration on a $15^{\circ}$ interval.

APR and HI Calculations: The USEPA approved methodology has been used in this study to asses the estimated population effected by the carcinogenic properties of benzene via inhalation as a route of exposure. Ambient concentration values were used and recorded every five minutes but averaged over an hour period. The risk factor for benzene was calculated using the following equations to determine the exposure intake in $\left(\mathrm{mg} \mathrm{kg}^{-1} \mathrm{day}^{-1}\right)$ :

$$
E=\frac{C \cdot C R \cdot E F \cdot E D}{B W \cdot A T}
$$

Where $\mathrm{C}$ is the contaminant concentration in $\mathrm{mg} . \mathrm{m}^{-3}$; $\mathrm{CR}$ is the contact rate in $\mathrm{m}^{3} \mathrm{day}^{-1}$; $\mathrm{EF}$ is the exposure frequency in days per year; ED exposure duration (year); BW is the average human body weight $(\mathrm{kg})$; AT is the averaging time in hours per year $=70 \times 365$ for carcinogens. Typical values for the given parameters were used as described in Table 2. Thus; $E=0.1174$ $m g\left(\mathrm{~kg}^{-1} d a y^{-1}\right)$ and $\mathrm{Ti}=\mathrm{E} \times \mathrm{SFi}$, where $\mathrm{T}$ is the toxicity factor for chemical $i$ and SF is the cancer slope factor or the cancer potency factor in $\left[\mathrm{mg} \mathrm{kg}^{-1} \mathrm{day}^{-1}\right]$. SF value is $0.029\left[\mathrm{mg} \mathrm{kg}^{-1} \mathrm{day}^{-1}\right]$ for benzene. The risk factor $\mathrm{Ri}$ is 
equal to the product of the concentration of the chemical in $\mathrm{mg} / \mathrm{m}^{3}, \mathrm{Ci}$ and Toxicity factor, Ti. Following the calculation of the previous mentioned parameters, the annual population risk was calculated (equation 3).

Table 2: Typical values used in the calculations given by the National Institute for Occupational Safety and Hazards, NIOSH

\begin{tabular}{cc}
\hline CR & $20 \mathrm{~m}^{3}$ day $^{-1}$ \\
\hline EF & 350 days year \\
BW & $70 \mathrm{~kg}$ \\
$\mathrm{ED}$ & 30 years \\
\hline
\end{tabular}

Annual Population Risk $=$ Risk factor $\mathrm{x}$ Population / lifetime

To generalize the study for the entire state of Kuwait, 70 years was considered as life time average of citizens as well as a million's population for all Kuwaitis that live within the borders of the state. Hazard Index (HI) calculations were considered to be the most reliable parameter for determination of safe sites. Equation 4 show the HI calculation based on atmospheric levels of pollutants as used in this study. If $\mathrm{HI}$ is less than unity the work place or site is considered safe ${ }^{[6]}$.

$\mathrm{HI}=\Sigma(\mathrm{Ci} / \mathrm{PELi})$

Where $\mathrm{Ci}$ is the concentration of $\mathrm{i}$ in $\mathrm{mg} / \mathrm{m}^{3}$; PELi is the permissible exposure limit for $\mathrm{i}$ in $\mathrm{mg} / \mathrm{m}^{3}$.

Preliminary analysis: Figure 1 is a $15^{0}$ span concentration rose for the month of June 2005 indicating MAA refinery $\left(135^{\circ}-255^{\circ}\right)$ as the dominate source; in a blowing from option, pollution source related to the human activities from the housing area. The rose is drawn for methane gas using unfiltered data. Figures 2 is a concentration rose for $\mathrm{SO}_{2}$ chosen for the year 2005, for the month of January 2005. $\mathrm{SO}_{2}$ is mainly emitted from the refineries and is clearly showing 105-165 deg. Sector as the major source. The other industries as well contribute to the background concentrations of a variety of airborne pollutants. The ozone precursor VOCs, NOx and sunlight result into the buildup of ozone concentration in the ambient air. High concentration of ozone was established from the downtown side in a wide span due to the presence of its precursor concentrations and also being secondary pollutant. Cloud covers as well as NOx concentrations are the major influencing parameter for ground level ozone concentrations. Since NO neutralizes ozone as the concentration of NO builds up during combustion processes the concentration of ozone almost diminishes. In the filtration process, as mentioned in the receding sections, the NO concentration has a counter pattern of that of the ozone. This effect is commonly known as the titration effect. The $\mathrm{NO}$ is oxidized to $\mathrm{NO}_{2}$ in the presence of oxidizing agent like $\mathrm{OH}^{-}$and ozone. Therefore, ozone concentration is minimum in the presence of strong source of NO but NOx concentration is the true indication of the presence of combustion source. The total percent of the filtered data recorded was about $97 \%$ which is considered a regular portion of data; i.e.: $3 \%$ of data points were discarded.

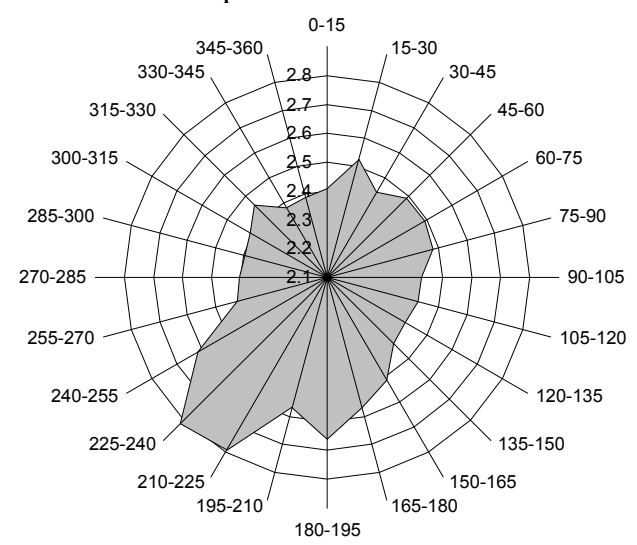

Fig. 1: Unfiltered concentration rose for the month of June 2005, methane gas.

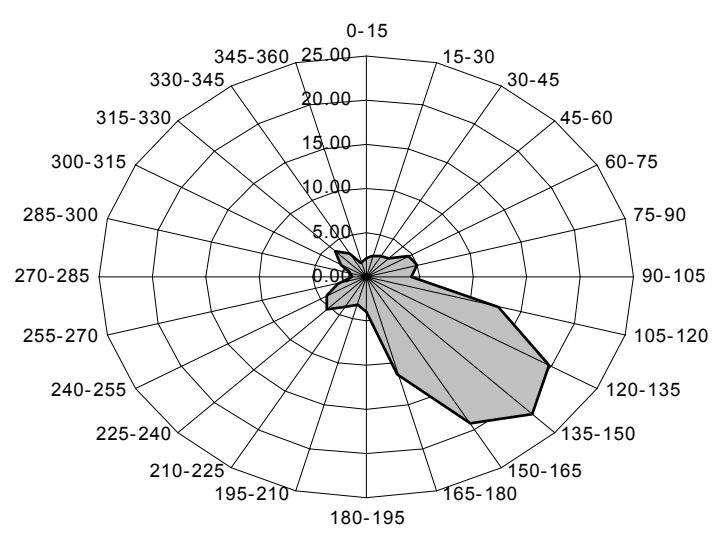

Fig. 2: Unfiltered concentration rose for the month of January $2005, \mathrm{SO}_{2}$.

\section{RESULTS AND DISCUSSION}

The unfiltered roses gave an initial feel of the area under investigation outdoor air quality. A series of 
filtered concentration roses were executed for the primary and secondary pollutants measured in the area, focusing on benzene $\left(\mathrm{C}_{6} \mathrm{H}_{6}\right)$. Figure 3 shows the concentration rose of benzene for the month of December 2004. The predominant refineries side of the area was clearly contributing in great proportions with respect to other wind directions.

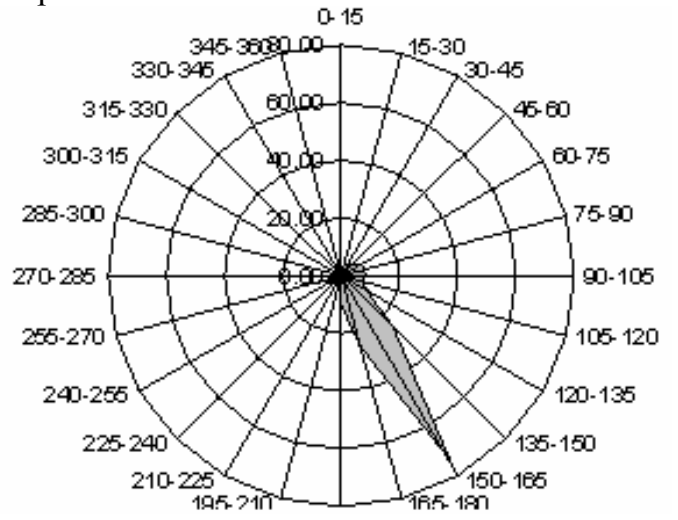

Fig. 3: Filtered concentration rose for the month of December 2004, Benzene

Over the course of the study, benzene levels were increasing gradually. Replacement of PRILLING processes in Petrochemical industries and the retirement of Shuwibah Refinery in the state of Kuwait, over loaded and over worked the other two refineries to over $110 \%$ of their working capacities and specs. This all resulted in benzene and ammonia emissions that exceeded the limits of KUEPA rules and regulations Figure 4 show benzene rose plotted for January 2005, were the contribution of the southwest area of petrochemicals in the state of Kuwait was starting to be noticed.

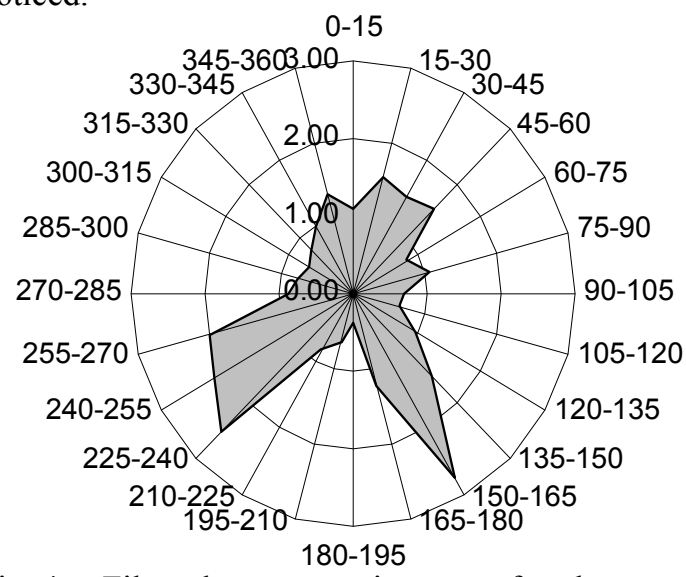

Fig. 4: Filtered concentration rose for the month of December 2005, January.
The concentrations of other pollutants were monitored in a regular fashion every five minutes interval with high precision and was recorded continuously on a data acquisition system. Toluene doubled in the period of study, from $1.5 \mathrm{ppb}$ to $3 \mathrm{ppb}$. Xylenes had an annual mean of $0.4 \mathrm{ppb}$ in the year 2004, which increased to a mean value of $2.4 \mathrm{ppb}$ in the year 2005. The main source of these compounds is known to be the oil refineries and petrochemical industries in the vicinity of this residential area ${ }^{[7-9]}$. Oil production, from oil wells to booster stations, gathering centers operations (desalting, dehydration, sweetening etc) results into pit fire and flares to dispose accumulation of heavy hydrocarbon waste ${ }^{[9]}$. These activities provide background high concentration of non-methane hydrocarbons. Other PAH's (Polycyclic Aromatic Hydrocarbons) were noticed to be increasing in the ambient due to the above-mentioned reasons. Another undesirable pollutant found in the ambient air was Chlorine $\left(\mathrm{Cl}_{2}\right)$. The alarming threat these chemicals pose to the human health especially after the doubling of the annual mean (2004 was $0.1 \mathrm{ppm}$ and in 2005 the annual mean was calculated to be $0.21 \mathrm{ppm}$ ). Chlorine is produced in salt and chlorine plant and is extensively used in desalination and water distribution systems. Chlorine has extensive use in inoculation of tertiary treated wastewater from all wastewater treatment plants ${ }^{[4]}$. There is also extensive application of chlorine and chlorine products in domestic clean and inoculation. Leukemia and lung cancer and other diseases concerning respiratory organs are direct result of exposure to such pollutants. Hydrogen Sulfide $\left(\mathrm{H}_{2} \mathrm{~S}\right)$ had a similar trend in the study period. The annual mean was calculated to be $2.1 \mathrm{ppb}$ in 2004 and $5.2 \mathrm{ppb}$ in the following year. The overbearing influence of petroleum refineries and petrochemical industries are due to aging refining units those are either being phased out or upgraded. The phase out of the oldest refinery in the state of Kuwait demands extra working conditions from the one under investigation in this study. Never the less, the $\mathrm{H}_{2} \mathrm{~S}$ is emitted from many sources from the south side of Fahaheel. Gas plant, sweetening process, sulphur recovery plants (mainly in Shuiabah industrial area) and all the hydro-desuphurization units in refineries are the main contributors of sulphur compounds in the ambient air.

The objective of this study was mainly estimating cancer risk by calculating the annual population risk. The calculations were based on 70 years average to standardize the study. Mean values of the three years were used to estimate the annual population risk (table $3)$. 
Table 3: Annual population risk calculated based on ambient benzene levels.

\begin{tabular}{cccc}
\hline Year & $\begin{array}{c}\text { Benzene mean } \\
\text { ambient level } \\
(\mathrm{ppb})\end{array}$ & $\begin{array}{c}\text { SF } \\
\left(\mathrm{mg} \mathrm{kg}^{-1} \text { day }^{-}\right.\end{array}$ & $\begin{array}{c}\text { APR } \\
(\text { People/Residence } \\
\text { (1) }\end{array}$ \\
\hline 2004 & 1.1 & & 17 \\
2005 & 1.6 & 0.029 & 20 \\
2006 & 1.8 & & 22 \\
\hline
\end{tabular}

Table 4: HI results based on inorganic pollutants monitored.

\begin{tabular}{lllll}
\hline Pollutant & $\begin{array}{l}\text { PEL } \\
(\mathrm{ppb})\end{array}$ & $\begin{array}{l}\text { Ambient } \\
\text { level }\end{array}$ & HI & Month/Year \\
\hline & & 18.6 & 0.00372 & $\mathrm{Jan} / 06$ \\
$\mathrm{SO}_{2}$ & 5 & 19.7 & 0.00394 & $\mathrm{Feb} / 06$ \\
$(\mathrm{ppb})$ & & 24.0 & 0.0048 & $\mathrm{March} / 06$ \\
& & 31.5 & 0.0063 & $\mathrm{Jan} / 06$ \\
$\mathrm{NO}_{2}$ & 5 & 31.5 & 0.0063 & $\mathrm{Feb} / 06$ \\
$(\mathrm{ppb})$ & & 44 & 0.0088 & $\mathrm{March} / 06$ \\
& & 25.9 & 0.000518 & $\mathrm{Jan} / 06$ \\
$\mathrm{NH}$ & 5 & 85.3 & 0.001706 & $\mathrm{Feb} / 06$ \\
$(\mathrm{ppb})$ & & 84.9 & 0.001698 & $\mathrm{March} / 06$ \\
\hline
\end{tabular}

Based on the above calculation in 2006, 22 cases were affected by benzene in the monitored area. These numbers are based on benzene levels as well as being of atmospheric load. Health risk assessment is based on personal exposure limits. HI calculations revealed that the area studied was considered safe for living purposes when it comes to non-organic ambient matters (table 4). The HI summation gave a 0.034 summation which is less than unity in all duration. The carcinogenic risk is the one threatening the area in this case. Many sites in the GCC region area under the same threat ${ }^{[6]}$. The effect is increasing annually. Regular monitoring as well as preventive maintenance are a must in such cases. Industrial sites surrounding the monitored area must be under constant surveillance.

\section{CONCLUSION}

Based on ambient levels the hazard index (HI) was calculated for the investigated area $(\mathrm{HI}=0.03)$ resulting in a safe index for living conditions. However, the annual population risks based on benzene levels were increasing annually. The 2006 mean average resulted in a 22 cases from the previous analysis and calculations. Other pollutants were monitored as well were levels of chlorine and $\mathrm{H}_{2} \mathrm{~S}$ were noticed to have increased. The retirement of the third refinery in the state of Kuwait resulted in overworking other downstream facilities. KUEPA rules and regulations must be forced upon such industrial facilities with a regular monitoring plan.

\section{REFERENCES}

1. Kuwait Ministry of Health (MOH), 2006. Cancer casualties and treatment tables, Tech. Report., Government press.

2. Al-Salem, Sultan M., and Al-Haddad, Amir A., 2006. Pollutants Monitoring and Source Determining: Effect of Oil Refineries on a Residential Area, Proc. of the $2^{\text {nd }}$ Int. Conference on Scientific Computing to Computational Engineering ( $2^{\text {nd }}$ IC-SCCE), Edited By: Professor. Demos T. Tsahalis, Set No: 960-530-080-X, Athens, Greece.

3. Al-Salem, Sultan M., and Khan, Abdul Rehamn; 2006. Methane Dispersion Modeling and Source Determination around Urban Areas in Kuwait, Proc. $1^{\text {st }}$ Int. Conference and Exhibition on Green Industry, Manama, Bahrain.

4. Morello-Frosch, R.A., Woodruff, T.J., Axelrad, D.A.; Caldwell, J.C., 2000. Air Toxics and Health Risks in California: The Public Health Implications of Outdoor Concentrations, Risk Analysis, 20(2): 273-292.

5. Smith, Roy L., 1994. Use of Monte Carlo Simulation for Human Exposure Assessment at a Superfund Site, Risk Analysis, 14(4): 433.

6. Al-Salem, S.M. and Bouhamrah, W.S., 2006. Ambient Concentrations of Benzene and Other VOC's At Typical Industrial Sites in Kuwait and Their Cancer Risk Assessment, Research Journal of Chemistry and Environment, 10(3): 42-46.

7. Al-Salem, Sultan M.S., Al-Haddad, Amir A. and Khan, Abdul Rehman, 2007. Chemical Processes Effect on Ambient Air Quality: Modeling and Primary/Secondary Pollutants Monitoring Study, WIT Transaction on Ecology \& The Environment (ISSN 17433541) \& Proc. Air Pollution 2007/Fifteenth Int. Conference on Modeling, Monitoring and Management of Air Pollution, Algarve, Portugal.

8. Al-Salem, S.M.S., 2007. Dispersion Modeling Using Modified Gaussian Model, Proc. $2^{\text {nd }}$ Int. Conference on Experiments/Process/System Modeling/ Simulation \& Optimization ( ${ }^{\text {nd }}$ ICEpsMso), Edited By: Professor: Demos T. Tsahalis, Set No: 960-530-090-7, Athens, Greece.

9. Al-Salem, Sultan M.S., Khan, Abdul Rehman and Al-Samhan, Meshal M., 2007. Downstream Effect on Ambient Benzene Levels in Fahaheel Urban Area in the State of Kuwait: Cancer Risk Assessment and Annual Population Risk Study, Proc. $4^{\text {th }}$ int. Health, Safety, Environment, and loss prevention, professional development conference \& exposition, Kuwait, The State of Kuwait. 